\title{
Letter to the Editor on "Feedback Methods in an Interprofessional Mock Paging Program"
}

\author{
Kalyani Nair $^{1}$ (D) Charlotte Muehlschlegel $^{1} \cdot$ Pia Borgas $^{1}$
}

Accepted: 7 January 2022 / Published online: 21 January 2022

(c) Crown 2022

\section{Dear Editor,}

We would like to congratulate Mutter et al. on publishing an original piece of research on novel teaching methods for students [1]. We would like to make some contributions, whilst drawing on some of our own experiences as junior doctors.

Medical school curricula utilise a combination of theoretical and practical-based education, with a more recent emphasis on self-directed and student-centred learning. However, it has been shown that completing sessions that require active involvement where the student is fully engaged throughout (e.g. simulation) is more effective for building long-term confidence [2]. Therefore, the use of simulation is increasing, providing a safe space for students to practice [3].

We agree that feedback is crucial for self-improvement, although it should be provided in a constructive and positive way, as it can have a significant impact on students' mental wellbeing [4]. This research demonstrates that receiving direct verbal feedback immediately after the phone calls instead of at the end led to a more significant improvement, thereby demonstrating how crucial constant feedback is to improving practice [1].

We received reports that UK final-year medical students did not feel adequately prepared to become a qualified doctor, and this is extensively supported by literature [5], although it is improving as curricula change [6]. Most papers on similar courses appear to be from the USA, and we argue that there is a need for similar programmes within the UK. As a result, we are currently running a similar course for final-year students during which students are "bleeped" to complete tasks around the hospital and have to use the SBAR format to give and receive handovers, receiving immediate and delayed feedback.

Kalyani Nair

kalyani.nair1@nhs.net

1 Department of General Surgery, North Middlesex University Hospital NHS Trust, London N18 1QX, UK

Author Contribution All authors discussed, wrote and edited the manuscript. All authors read and approved the final manuscript.

Data Availability Data sharing is not applicable to this article as no datasets were generated or analysed.

\section{Declarations}

Conflict of Interest The authors declare no competing interests.

\section{References}

1. Mutter MK, Pedersen K, Cunningham T, et al. Feedback methods in an interprofessional mock paging program. Med Sci Educ. 2021. https://doi.org/10.1007/s40670-021-01445-1.

2. Schwind CJ, Boehler ML, Markwell SJ, Williams RG, Brenner MJ. Use of simulated pages to prepare medical students for internship and improve patient safety. Acad Med. 2011;86(1):77-84. https:// doi.org/10.1097/ACM.0b013e3181ff9893 (PMID: 21099392).

3. Buist N, Webster CS. Simulation training to improve the ability of first-year doctors to assess and manage deteriorating patients: a systematic review and meta-analysis. Med Sci Educ. 2019;29(3):749-761. https://doi.org/10.1007/s40670-019-00755-9 
4. Shrivastava SR, Shrivastava PS, Ramasamy J. Effective feedback: an indispensable tool for improvement in quality of medical education. Journal of Pedagogic Development. 2014;4.

5. Brennan N, Corrigan O, Allard J, Archer J, Barnes R, Bleakley A, Collett T, de Bere SR. The transition from medical student to junior doctor: today's experiences of tomorrow's doctors. Med Educ. 2010;44(5):449-58. https://doi.org/10.1111/j.1365-2923. 2009.03604.x (PMID: 20518984).

6. Cave J, Goldacre M, Lambert T, Woolf K, Jones A, Dacre J. Newly qualified doctors' views about whether their medical school had trained them well: questionnaire surveys. BMC Med Educ. 2007;7:38. https://doi.org/10.1186/1472-6920-7-38
7. Frischknecht AC, Boehler ML, Schwind CJ, Brunsvold ME, Gruppen LD, Brenner MJ, Hauge LS. How prepared are your interns to take calls? Results of a multi-institutional study of simulated pages to prepare medical students for surgery internship. Am J Surg. 2014;208(2):30715. https://doi.org/10.1016/j.amjsurg.2014.01.014 (Epub 24 April 2014 PMID: 24933670).

Publisher's Note Springer Nature remains neutral with regard to jurisdictional claims in published maps and institutional affiliations. 